\title{
Aplicaciones de la inyección de grasa en Cirugía Plástica Reparadora y Estética. Nuestra evolución y estado actual
}

\section{Lipofilling applications in Reconstructive and Aesthetic Plastic Surgery. Our evolution and current situation}

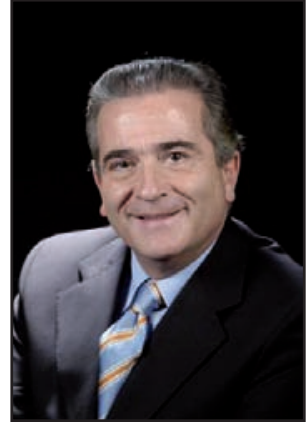

Serra-Renom, J.M.

\section{Serra-Renom, J.M.*}

La inyección de grasa se ha establecido como una técnica coadyuvante ampliamente usada tanto en Cirugía Estética como en Cirugía Reparadora, probablemente por su capacidad para reemplazar el tejido con uno similar (replace like with like), que es uno de los principios de la cirugía conservadora descrita por Converse. La suficiente disponibilidad de tejido donante, la baja morbilidad en la zona liposuccionada, incluso el beneficio que aporta para la paciente, su biocompatibilidad y facilidad de aplicación, han sido algunos de los factores determinantes de su reciente expansión.

El primer trabajo que se publicó en España sobre la aplicación de la inyección de grasa en Cirugía Plástica, data del año 1985, en un número monográfico de la Revista Iberolatinoamericana dedicado a la liposucción. En este número describimos la remodelación de deformidades postraumáticas mediante la liposucción de acúmulos grasos periféricos y el lipofilling o inyección de grasa en las depresiones centrales, en secuelas traumáticas para regularizar las superficies y aportar volumen. Sin embargo, hoy por hoy no sólo podemos considerar a la grasa como un material de relleno autólogo a modo de "filler". El tejido adiposo humano se ha convertido en una de las principales herramientas de trabajo en la ingeniería tisular. Esto se debe a que es un tejido con una población celular (stem cells adultas) capaz de proliferar y diferenciarse a múltiples tipos celulares: nuevos adipocitos, miocitos, osteoblastos..., además de contener un gran número de factores de crecimiento (GF's).

Recientemente se ha demostrado que el tejido adiposo contiene también células endoteliales progenitoras participadoras de la neoangiogénesis, vinculadas con la viabilidad de estos injertos. Procesos que son también estimulados especialmente por tres GF's propios del tejido adiposo humano: b-Fibroblast Growth Factor, Vascular Endotelium Growth Factor, Platelet Derived Growth Factor-BB.
Desde el primer trabajo que publicamos en el 85 hemos desarrollado distintas líneas de investigación tanto en el ámbito de la Cirugía Reparadora como de la Cirugía Estética.

Dividimos la exposición de las distintas aplicaciones de la lipoinfiltración y nuestra experiencia con el injerto graso en 4 apartados:

1) Aplicaciones de la lipoinfiltración en la región facial.

2) Aplicaciones de la lipoinfiltración en la cirugía mamaria.

3) Últimos avances.

4) Constitución de la Sociedad Española de Trasplante de Grasa (SETGRA).

\section{Aplicaciones de la lipoinfiltración en la región facial}

Tratamiento de las lipodistrofias en pacientes VIH

Desde el año 2000 empezamos a utilizar la lipoinfiltración para el tratamiento de la lipodistrofia facial en pacientes afectos de VIH y tratados con retrovirales. Desarrollamos primero la técnica en el Hospital Quirón de Barcelona (España) y luego en el Hospital Clínico de la misma localidad, donde creamos una línea de investigación y publicamos nuestros resultados en la revista Plastic and Reconstructive Surgery en el año 2004, siendo la primera publicación internacional en revistas con peer review, en lo que se refiere a la utilización de la lipoinfiltración para el tratamiento de las lipodistrofias faciales en pacientes afectos de VIH. Estos resultados fueron también incluidos en el capítulo 163 de la tercera edición del libro editado por el Dr. Felipe Coiffman "Cirugía Plástica Reconstructiva y Estética" del año 2007. Sin embargo, y a pesar de obtener resultados satisfactorios, decidimos cuantificar el porcentaje de reabsorción grasa con esta técnica. En el año 2008 y siguiendo esta 
línea de investigación dirigí la tesis doctoral del Dr. Joan Fontdevila relacionada con la lipoinfiltración en los pacientes con lipodistrofia mediante la medición con TAC de la permanencia y viabilidad del injerto graso. En nuestros estudios cuantitativos con TAC demostramos la permanencia en gran medida de los injertos grasos inyectados en esta región si la grasa se inyecta correctamente.

En el año 2009, el Dr. Coleman nos pidió que participáramos con un capítulo en su libro "Fat Injection From Filling To Regeneration”, en donde explicamos el tratamiento de la lipodistrofia con lipoinfiltración.

En la actualidad seguimos trabajando en este campo y hay ya una línea de investigación consolidada en la Universidad de Barcelona.

\section{Tratamiento del vector negativo facial}

También en la región facial, la lipoinfiltración ha sido uno de nuestros principales campos de trabajo en el ámbito de la cirugía estética facial.

El envejecimiento facial es un proceso dinámico que implica no sólo un proceso de atrofia, aumento de laxitud y redistribución de los tejidos blandos, sino también la alteración morfológica de ciertas estructuras óseas como consecuencia de la desmineralización, dando como resultado una pérdida de proyección de la zona malar que provoca que el párpado inferior, visto de perfil, aumente en longitud y el ángulo de la mejilla quede posterior a la superficie de la córnea, a lo que llamamos vector negativo facial. La técnica de lipoinfiltración malar consigue una muy buena remodelación del óvalo facial y la corrección del vector negativo, con un muy bajo índice de complicaciones y resultados altamente satisfactorios y estables.

En este ámbito, ya en el año 1987, en el libro que escribí con el Dr. Vila Rovira "Liposucción en Cirugía Plástica y Estética" editado por la editorial Salvat, en el capítulo 15, expusimos la utilización de la jeringa para obtener la grasa y después inyectarla en la cara. Fue un primer avance, pero estos injertos se reabsorbían porque rompíamos la grasa al extraerla con aguja y además, después no separábamos los ácidos grasos rotos, con lo cual el pH de lo que inyectábamos era pH ácido.

Posteriormente, y utilizando el método de procesamiento del tejido graso descrito por Coleman, publicamos en Cirugía Plástica Iberolatinoamericana en el año 2005, el uso de la lipoinfiltración facial para aumentar el pómulo, unida a los factores plaquetarios para conseguir así un mejor efecto antiinflamatorio y que nos prendiera mejor el injerto.

Siguiendo en esta línea, en el año 2011 hemos publicado en la revista Ophthalmic Plastic Reconstructive Surgery nuestra experiencia en 142 pacientes, destacando la importancia de corregir el vector negativo facial para obtener un buen rejuvenecimiento asociado al estiramiento facial.

\section{Aplicaciones de la lipoinfiltración en la cirugía mamaria}

Éste es otro apartado importante en el que estamos trabajando.

Desde los años 80 ha existido una gran controversia respecto a si se deben o no utilizar injertos de grasa en esta región anatómica por la posible modificación de la imagen radiológica tanto en mamografía como en resonancia magnética (RM), lo que podría dificultar el control radiológico tras la intervención y la interferencia en la detección precoz del cáncer de mama. $\mathrm{Al}$ respecto cabe decir que en primer lugar cualquier actuación sobre la glándula mamaria, por ejemplo, la colocación de unas prótesis mamarias, aumenta 20 veces más la Aromatasa que con la lipoinfiltración.

En cuanto a los hallazgos radiológicos tras la inyección de grasa, señalar que no son patognomónicos de crecimiento tumoral; antes bien son imágenes por lo general bien diferenciadas y que el radiólogo actual debe aprender y conocer, al igual que ha tenido que familiarizarse con las modificaciones aparecidas en otras cirugías mamarias convencionales (reducción, aumento, pexia...) y que son comúnmente aceptadas. En esta misma línea, debemos hablar sobre las microcalcificaciones que se producen cuando crece una célula tumoral en un carcinoma intraductal y rompe el parénquima mamario provocando una pequeña hemorragia. Esta sangre, que lleva calcio, produce esas microcalcificaciones que son completamente distintas a las calcificaciones que aparecen con lipoinfiltración y también a las que aparecen con otras cirugías mamarias como la reducción, pexia, etc. Pensamos que lo más adecuado es que el radiólogo progrese con nosotros y aprenda a valorar este tipo de imágenes y a diferenciar las calcificaciones de la lipoinfiltración de las microcalcificaciones debidas al crecimiento tumoral.

\section{Reconstrucción mamaria}

En los casos en los que usamos la lipoinfiltración como adyuvante a la reconstrucción mamaria, partimos de una mama que ya presenta cicatrices y calcificaciones como consecuencia de la extracción del tumor.

La ASPS Fat Graft Task Force en su publicación del 2009, actualizó su recomendación sobre el uso de la inyección de grasa.

Desde el año 2006 hemos empezado a usar la lipoinfiltración en cirugía mamaria en muchos campos, y fue en el año 2009 cuando el Catedrático de la Universidad Autónoma de Barcelona, Profesor Luis Cabero, nos pidió que publicáramos en su revista "Folia Clínica en Obstetricia y Ginecología" un número monográfico con 6 trabajos sobre la utilización de grasa en cirugía mamaria. En este monográfico explicamos el porqué de la utilización de la grasa en mama, la importancia de que el radiólogo efectúe un diagnóstico diferencial del lipo- 
infiltrado respecto a otras calcificaciones, expusimos la utilización de la grasa en el aumento mamario, en las asimetrías mamarias con corrección quirúrgica y la lipoinfiltración del lado contralateral para simetrizar; también la utilización de la lipoinfiltración para corregir las secuelas de las tumorectomías.

Cuando una paciente necesita una mastectomía y no desea que se le reconstruya la mama con tejido de la espalda porque tiene una dermis mucho más gruesa que la dermis de la piel torácica, o no quiere una doble isla de piel insensible obtenida de la zona glútea o de la zona abdominal, pensamos que es muy útil la utilización de expansores con prótesis; pero es un hecho que cuando una paciente que requiere una mastectomía debe someterse a un tratamiento con radioterapia, en la bibliografía internacional está contraindicado el uso de prótesis y expansores en los tejidos radiados. Nosotros trabajamos con lipoinfiltración en estos casos y después de 5 años, hemos publicado nuestra experiencia sobre la utilización de lipoinfiltración en pacientes a las que se les colocaba un expansor y una prótesis y habían sido radiadas, demostrando que se producía un nuevo tejido subcutáneo gracias al lipoinfiltrado. Esta publicación ha sido referenciada más de 49 veces en la bibliografía internacional y está citada también en tres capítulos en la enciclopedia más actual de Cirugía Plástica publicada por Neligan.

Otra aplicación del lipoinfiltrado en la reconstrucción mamaria es la reconstrucción mamaria solamente con grasa. Cuando una paciente ha sufrido una mastectomía lo suficientemente conservadora, con piel elástica y flacidez, hemos podido reconstruir la mama mediante varias sesiones de lipoinfiltración sin el método Brava y efectuando una pexia del tejido graso inyectado. Esta técnica la hemos publicado en la revista Annals of Plastic Surgery en el año 2011.

Cuando tenemos una paciente que presenta un tumor menor de $2 \mathrm{~cm}$ en el cuadrante superior externo de la mama, realizamos una cuadrantectomía con endoscopia a través de una incisión periareolar de 9 a 3 (en la imagen de las agujas de un reloj) y una incisión axilar. Desde esta incisión axilar, además de detectar el ganglio centinela o de llevar a cabo la disección axilar, procedemos a la disección del músculo dorsal ancho con endoscopia, sin hacer ninguna cicatriz en la espalda. Esta técnica la hemos publicado en Aesthetic Plastic Surgery Journal del año 2013. La única secuela que queda es una pequeña depresión a nivel del reborde de la espalda, donde hemos obtenido todo este fascículo de músculo dorsal ancho, y esta depresión la corregimos con lipoinfiltración para simetrizar con respecto al lado contralateral.

\section{Mamas tuberosas}

También hemos empleado la grasa para la corrección y simetrización de las mamas tuberosas; corregimos las mamas tuberosas grado III mediante la técnica de Puc- kett y abriendo el tejido glandular como un lomo de libro; en estos casos el lipoinfiltrado nos ayuda a simetrizar las dos mamas. Publicamos este método en Aesthetic Plastic Surgery en el año 2011. En las mamas tuberosas de grado I y II hemos visto que se puede realizar un aumento mamario con prótesis y corregir el efecto de doble surco que aparece (double bubble) con lipoinfiltración a nivel subcutáneo. Igualmente hemos aplicado la lipoinfiltración para corregir este efecto en las cirugías de aumento mamario simple, lo que hemos publicado en Aesthetic Plastic Surgery en el año 2012.

\section{Últimos avances}

Otro apartado que quería exponer en este artículo editorial son los caminos a los que nos estamos dirigiendo de cara al futuro. Pensamos que tanto el banco de grasa con criopreservación será muy importante, así como también la utilización de la Fracción Estromal Vascular.

\section{Banco de tejido graso criopreservado}

Una vez transplantado el injerto, hasta que se da lugar a la neoformación de vasos y la subsiguiente integración en el tejido receptor, la grasa sobrevive principalmente por difusión. Estas características biológicas son el principal factor limitante cuando se requiere la reconstrucción de grandes volúmenes, lo que ocasiona que su inyección deba fraccionarse en varios tiempos quirúrgicos, como ocurre cuando se quiere reconstruir una mama, desechando gran parte del volumen graso aspirado u obligando a realizar varias pequeñas liposucciones.

En este tipo de casos, mediante una liposucción a baja presión previa tumescencia, y con una cánula de $3 \mathrm{~mm}$, efectuamos una liposucción amplia. Seguidamente limpiamos esta grasa con Ringer lactato y la colocamos en bolsas de 150 cc que se envían al Banco de grasa, donde la procesan correctamente con agentes crioprotectores (como el dimeyil sulfóxido- DMSO...) y la someten a una reducción progresiva de la temperatura para proteger las células adiposas y para que además de ser viables, después de la descongelación conserven sus propiedades funcionales.

Nosotros hemos puesto en marcha varias técnicas con la utilización del Banco de grasa. Una de ella es la sustitución de prótesis encapsuladas. Para ello, hacemos en el primer tiempo quirúrgico una liposucción abdominal o/y de la región trocantérea, en el mismo acto en el que extraemos la prótesis. A continuación tratamos la grasa, la centrifugamos y la colocamos en bolsas de $150 \mathrm{cc}$. En esta primera liposucción, si es posible, hacemos también la primera sesión de lipoinfiltración entre la piel y la cápsula. Cada 3 meses hacemos un nuevo lipofilling con una pequeña sedación y ambulatoriamente. Con dos o tres lipofillings conseguimos que la paciente tenga un aumento mamario satisfactorio solamente con su propio tejido graso obtenido con la liposucción. Pensamos que la con- 
gelación de la grasa criopreservada en un banco de grasa tiene un gran potencial en el futuro.

\section{Utilización de la Fracción Estromal Vascular}

Otro campo importante en el que estamos trabajando es la utilización de la Fracción Estromal Vascular (FEV), que en la literatura anglosajona también aparece con las siglas SVF por Stromal Vascular Fraction o ADRC por Adispose Derived Regenerative Cells. Este componente lo obtenemos mediante el tratamiento enzimático de la grasa, principalmente mediante colagenasas, con el método Celution $^{T M}$ (Cytori Therapeutics, Inc., EE.UU). Con este método, por cada gramo de grasa limpia se obtiene una población multicelular de aproximadamente 300.000 células, que se mezclan con $5 \mathrm{cc}$ de Ringer Lactato para su utilización (de estas células solo el $2 \%$ son células madre).

No hemos visto grandes ventajas del uso de la lipoinfiltración con grasa enriquecida respecto a la no enriquecida. En primer lugar porque se necesita obtener el doble de volumen, ya que la mitad se dedica a ser centrifugada y se obtienen $5 \mathrm{cc}$ de contenido estromal, con lo cual si sacamos 1 litro de grasa, y la mitad se procesa, se obtienen $5 \mathrm{cc}$ que se añaden a los $500 \mathrm{cc}$ de grasa para obtener un volumen total de $505 \mathrm{cc}$. En lo que sí estamos colaborando es en la obtención de la FEV con otras disciplinas, en concreto en Medicina Deportiva con el Dr. Cugat. Los deportistas profesionales en activo tienen muy poca grasa y es difícil obtenerla, pero sí que se puede conseguir un volumen de grasa suficiente de 300-400 cc que una vez procesada nos de una solución de $5 \mathrm{cc}$ para inyectar en las plastias tendinosas.

La utilización de todo el componente multicelular de la FEV nos da mejores resultados que el uso aislado de otras soluciones como los factores de crecimiento plaquetario PRP (Platelet Rich Plasma) aunque nuestros trabajos aún están en fase de realización y no podemos extraer conclusiones. Estos últimos actúan efectuando una señal paracrina pero de pocas horas de duración. En cambio las células contenidas en la FEV son células vivas que permanecen durante al menos una semana.

\section{Constitución de la Sociedad Española de Transplante de Grasa (SETGRA)}

El último apartado que quiero exponer en este editorial es acerca de la creación de la Sociedad Española de Trasplante de Grasa.

En el otoño del año 2008, en una reunión con mis amigos, los Doctores Jaime Monner, Jesús Benito Ruiz y Joan Fontdevila, nos planteamos la creación de la Sociedad Española de Trasplante de Grasa ya que era una inquietud científica importante y pensamos que la colaboración multidisciplinar de todos aquellos profesionales que se ocupan desde las bases biológicas del tejido graso, hasta aquellos que le damos un uso clínico, podía contribuir y ser de gran ayuda para avanzar en este campo. El 6 de febrero del año 2009 se registró oficialmente la Sociedad Española de Trasplante de Grasa (SETGRA) en el Ministerio del Interior en España.

El primer congreso se realizó en el Hospital Quirón de Barcelona en el año 2009, en colaboración con la Universidad Internacional de Cataluña, y en este congreso se nombró al Dr. Jaime Monner Miembro de Honor de la Sociedad por sus grandes aportaciones a la misma y porque ya nos había abandonado unos meses antes.

Después de este primer congreso han seguido otros congresos anuales que tienen mucha afluencia de asistente y han resultado de gran interés científico. Este año 2013 se realizará el V Congreso Nacional de la SETGRA en Barcelona.

\section{Dirección del autor}

Dr. José María Serra Renom

Instituto de Cirugía Plástica y Estética Dr. Serra-Renom Hospital Quirón Barcelona.

Plaza Alfonso Comin, 5-7

08023. Barcelona. España.

e-mail: serrarenom@gmail.com

\section{Bibliografía}

1. Serra Renom JM, Vila Rovira R, Recalde M.: Liposucción en Cirugía Reparadora (Desgrasado de colgajos cutáneos y miocutáneos, exéresis de acúmulos grasos y autotransplante de grasa). Cir plást iberolatinoam. 1985, 11:319-326.

2. Serra-Renom JM, Fontdevila J.; Treatment of facial fat atrophy related to treatment with protease inhibitors by autologous fat injection in patients with human immunodeficiency virus infection. Plast Reconstr Surg 2004; 114:551-555.

3. Serra Renom JM, Fontdevila J.: Tratamiento de la atrofia grasa facial mediante la inyección de grasa autóloga en pacientes infectados por VIH. In: F. Coiffman, ed. Cirugía Plástica, Reconstructiva y Estética $\left(3^{\circ}\right.$ ed). Colombia: Ed. AMOLCA, 2007, Pp:1413-1416.

4. Serra-Renom JM, Fontdevila J.: Treatment of HIV-related lipoatrophy. In: Sydney R. Coleman, Riccardo F. Mazzola, eds. Fat injection from filling to regeneration. St Louis: Quality Medical Publishing, Inc., 2009, Pp: 695-716.

5. Vila Rovira R, Serra Renom JM.: Microliposucción y Microinyección de grasa en la region facial. In: Vila Rovira R, Serra Renom JM, eds. Liposucción en cirugía Plástica y Estética. Barcelona, Salvat, 2007, Pp:153-163.

6. Serra Renom JM, Muñoz del Olmo J, Gonzalo Caballero C.: Uso de los Factores de Crecimiento plaquetar unidos a los injertos de grasa para el lipofilling facial en ritidectomías. Cir plást iberolatinoam. 2005; 32:191-198.

7. Serra-Renom JM, Serra-Mestre JM.: Periorbital rejuvenation to improve the negative vector with blepharoplasty and fat grafting in the malar area. Ophthal Plast Reconstr Surg. 2011, 27(6):442-446. 
8. Gutowski K.: Current Applications and Safety of Autologous Fat Grafts: A Report of the ASPS Fat Graft Task Force. Plast Reconstr Surg. 2009; 124:272.

9. Serra-Renom JM.: Inyección de grasa en la cirugía mamaria.(Número monográfico: Aumento, Tumorectomía, Asimetría...)Folia clínica en Obstetricia Ginecologia. 2009; 75:6.

10. Serra-Renom JM, Muñoz-Olmo JL, Serra-Mestre JM.: Fat grafting in post mastectomy breast reconstruction with expanders and prosthesis in patients who have received radiotherapy. Formation of new subcutaneous tissue. Plast Reconstr Surg. 2010,125:12-18.

11. Serra-Renom JM, Muñoz-Olmo JL, Serra-Mestre JM.: Breast Reconstruction with Fat Grafting alone. Ann Plast Surg. 2011; 66 (6): 598-601.
12. Serra-Renom JM, Muñoz-Olmo JL, Serra-Mestre JM.: Treatment of Grade 3 Tuberous Breasts with Puckett's Technique (Modified) and Fat Grafting to Correct the Constricting Ring. Aesthetic Plast Surg. 2011, 35(5):773-781.

13. Serra-Renom JM, Muñoz-Olmo JL, Serra-Mestre JM.: Endoscopically Assisted Aesthetic Augmentation of Tuberous Breasts and Fat Grafting to Correct the Double Bubble. Aesthetic Plast Surg. 2012, 36(5):1114-1119.

14. Serra-Renom JM, Serra-Mestre JM, Martinez L, D'Andrea F.: Endoscopic reconstrucción of partial mastectomy defects using latissimus dorsi muscle flap without causing scars on the back. Aesthetic Plast Surg. 2013, 37:941-949. 